\title{
Intratracheal Injection into Rats of Size-graded Silica Particles
}

\author{
B. GOLDSTEIN and I. WEBSTER \\ From the Pneumoconiosis Research Unit, Council for Scientific and Industrial Research, \\ P.O. Box 4788, fohannesburg
}

An experiment is described in which suspensions of size-graded silica particles of less than I $\mu, \mathrm{I}$ to $3 \mu$, and 2 to $5 \mu$ nominal size ranges and of equal surface area $(600 \mathrm{sq} . \mathrm{cm}$. $/ \mathrm{ml}$.) were injected intratracheally into rats. After four months the rats were killed and the lungs were examined histologically for the grade of fibrosis and chemically for the silica and collagen content.

The results were analysed statistically and it was found that, under the experimental conditions described, the degree of fibrosis produced by the two large size fractions was more than that produced by the under I $\mu$ particles and was apparently related to the quantity (by weight) of the silica injected or the size of the particles and not to the surface area.

In this experiment suspensions of silica particles of three different size ranges but of equal total surface area and hence containing different weights of silica were injected intratracheally into rats. After four months the lungs were examined histologically for the grade of fibrosis and chemically for the silica and collagen content.

\section{Experimental Procedure}

Dust Samples The suspensions of silica dust were prepared by the Transvaal and Orange Free State Chamber of Mines Dust and Ventilation Laboratory, Johannesburg and were of the size ranges less than I $\mu$, I to $3 \mu$, and 2 to $5 \mu$, of which $13.99 \mathrm{mg}$., $46 . \mathrm{I} \mathrm{mg}$., and $92.7 \mathrm{mg}$. were suspended in each ml. saline respectively. These concentrations were calculated to give a surface area of silica of $600 \mathrm{sq} . \mathrm{cm} . / \mathrm{ml}$. for each of the size ranges. Counts were done by means of the light and electron microscopes, and the details are given in Tables I to III, together with the $x$-ray and chemical analysis of the silica content. The $p \mathrm{H}$ of the suspensions was $6 \cdot 7,6.8$, and $7 \cdot 0$ for the 2 to $5 \mu$, I to $3 \mu$, and under I $\mu$ particles, respectively.

Using $\mathrm{Cu} \mathrm{K}$ alpha radiation, comparisons were made with the $x$-ray quartz standard, using the IoI reflection. The results are summarized in Table III.

They indicate that considerable peak broadening was present in both samples, no. 2 more than no. I. This would almost certainly be due to the crystallite

Received for publication July 2, 1965. size being smaller than that of the $x$-ray standard. Both samples would appear to be highly crystalline, the percentages probably being somewhat greater than the indicated values of $95 \%$ for sample $I$ and $94 \%$ for sample 2 , as the peaks were assessed over 2 degrees $(2 \theta)$, whereas the tails, although small, are thought to extend some considerable distance further. (The analysis was carried out by the Transvaal and Orange Free State Chamber of Mines Physical Science Laboratory.)

Animals Male white rats approximately 3 months old were divided into three groups by random selection. Thirty-five animals from each group were then given $\mathrm{I} \mathrm{ml}$. of the respective silica suspensions by the intratracheal method. Previous work (Goldstein, Webster, and Sichel, 1962) had shown that 25 to 30 animals from each group could be expected to produce statistically significant results and, to allow for deaths, five extra animals were used. One rat from each group was injected in rotation to avoid variation in technique favouring any particular group.

A number of animals died during the course of the experiment and the survivors, a total of 66 rats, were killed after four months. The body weight of each animal was recorded and then the lungs were removed. After ascertaining the wet weights of the right and left lungs separately, they were fixed in 10 $\%$ formol-saline, and histological sections were cut at $5 \mu$ and stained with haematoxylin and eosin and for reticulin. Without knowing to which group they belonged, the sections were examined for the 
TABLE I

Size Frequency Distribution of VARIOUS Size Fractions of the Dust: Electron Microscope Results

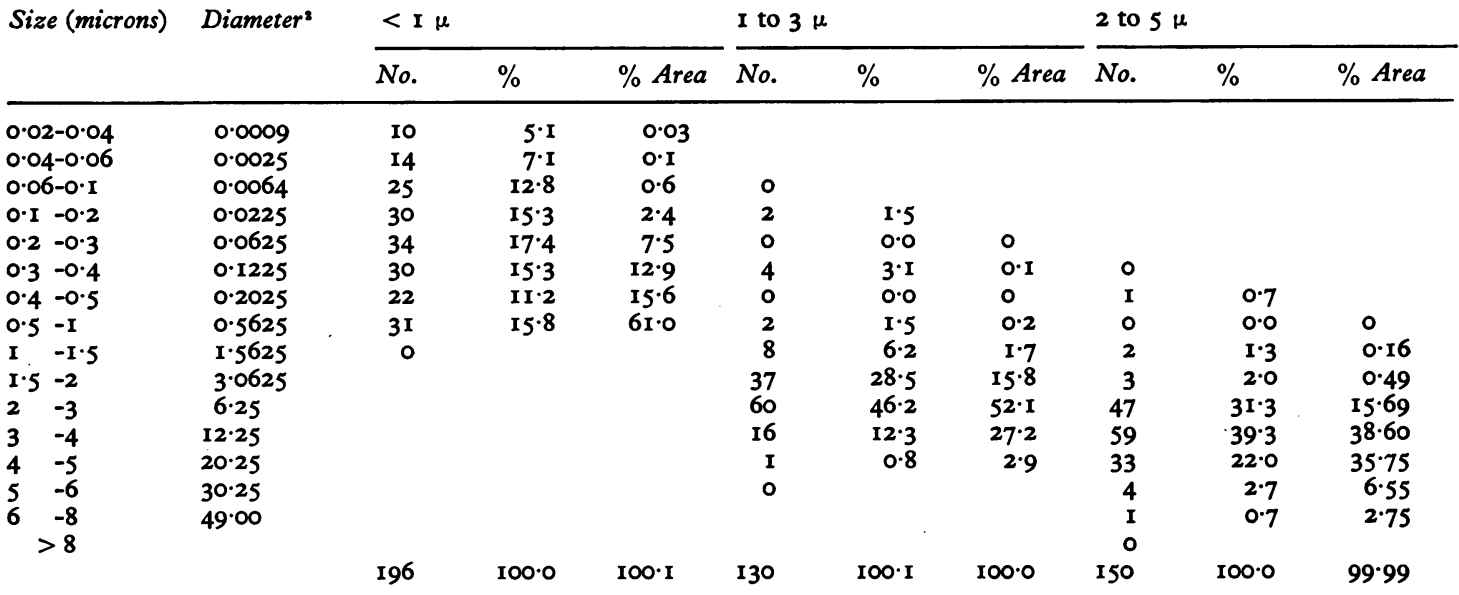

Notes

I. In column I the size refers to the diameters of circles of the same projected areas as the particles being sized.

2. The main headings of columns 3 to $I I$ refer to the nominal size ranges of the dust samples.

3. Under the heading 'No.' is given the actual number of particles counted for each size interval. This is followed by the number expressed as a percentage of the total number counted. These percentages are ali given to one decimal place, but when using them for calculations, the number of significant figures given in the result should be determined from the actual number of particles counted for the particular size range.

4. In the size fraction less than one micron, particles smaller than $0.02 \mu$ were not counted.

5. $\%$ Area $=$ Diameter $^{2} \times$ number $\%$.

TABLE II

$X$-RAY ASSESSMEnT OF QUARTZ

\begin{tabular}{lc} 
Sample & Response (\%) \\
\hline $2-5 \mu$ & 100 \\
$\mathrm{I}-3 \mu$ & 100 \\
Under I $\mu$ & 92 \\
& Chemical Analysis \\
$2-5 \mu$ & $99 \cdot 85 \%$ silica \\
$\mathrm{I}-3 \mu$ & $99 \cdot 85 \%$ silica \\
Under I $\mu$ & $99 \cdot 80 \%$ silica
\end{tabular}

presence of dust lesions, and these were graded by the number of lesions and the degree of fibrosis, according to the grading of Belt and King (1945), modified by omitting grade 5 and taking into consideration the number of lesions present (Goldstein, 1960). All the trimmings from the cutting were preserved and then dewaxed with the appropriate blocks, after which the tissue from the individual lungs was utilized for the chemical estimation of collagen and silica by the methods of Neuman and Logan (1950) and King, Stacy, Holt, Yates, and Pickles (1955) respectively. The results were then analysed statistically. 
TABLE IV

Number of Lungs Classified According to Number of Lesions and Degree of Fibrosis

Particle Size Histological Grading according to Number of Lesions

\begin{tabular}{|c|c|c|c|c|c|}
\hline $\begin{array}{l}\text { No Histological } \\
\text { Lesions or Destroyed } \\
\text { by Abscess }\end{array}$ & $\begin{array}{l}\text { Occasional } \\
\text { Nodules }\end{array}$ & $\begin{array}{l}\text { Ferw } \\
\text { Nodules }\end{array}$ & $\begin{array}{l}\text { Numerous } \\
\text { Nodules }\end{array}$ & $\begin{array}{l}\text { Confluent } \\
\text { Nodules }\end{array}$ & Total \\
\hline
\end{tabular}

\begin{tabular}{lrrrrrr}
\hline Under I $\mu$ & 9 & 4 & 22 & 15 & - & 50 \\
I $3 \mu$ & 9 & - & 4 & 9 & 26 & 48 \\
$25 \mu$ & 5 & - & 1 & 4 & 24 & 34 \\
Total & 23 & 4 & 27 & 28 & 50 & 132
\end{tabular}

Particle

Size

Histological Grading according to Degree of Fibrosis

\begin{tabular}{llllll}
\hline $\begin{array}{l}\text { No Histological } \\
\text { Lesions or Dstroyed } \\
\text { by Abscess }\end{array}$ & Grade I & Grade 2 & Grade 3 & Grade 4 & Total \\
\end{tabular}

Under I $\mu$

I-3 $\mu$

$2-5 \mu$

Total

9
9
5
23

$\frac{18}{18}$

respect to the different variables; and (3) a correlation between the different variables.

\section{Comparison between the Three Groups}

Body Weight of the Animals The average body weights of the three groups were found to be not significantly different from each other $(95 \%$ level of significance).

Wet Weight of Lungs per roog. Body Weight The average values for the three groups showed that at the $5 \%$ level there was no significant difference between the two larger particle sizes, but both these values were significantly higher than for the under I $\mu$ size. (The average values were $2 \cdot 23 \mathrm{~g}$. (under I $\mu$ ), $6.40 \mathrm{~g}$. (I to $3 \mu$ ), and $7.6 \mathrm{I} \mathrm{g.}(2$ to $5 \mu$ ).) It therefore appears that the relative increase in the wet weights of the lungs is dependent upon the size and/or weight of the dust injected.

Weight of Silica in Lungs From the average percentage recovery $(4 \mathrm{I} \%, 29 \%$, and $15 \%$ for the under I $\mu$, I to $3 \mu$, and 2 to $5 \mu$ groups respectively), it appears that the smaller particles are retained in the lungs more readily than the larger particles.

Weight of Collagen in Lungs The averages for the three groups were significantly different from each other and were $14.5 \mathrm{mg} ., 33.2 \mathrm{mg} ., 47.2 \mathrm{mg}$. for the under I $\mu, I$ to $3 \mu$, and 2 to $5 \mu$ particles respectively, with the weights of right and left lungs combined. This indicates a relation between the quantity or size of silica injected and the amount of collagen formed, but this relation is not directly proportional.

Histological Grading Contingency tables (Table IV) showed that the fibrosis caused by the I to $3 \mu$ and 2 to $5 \mu$ particles was much more severe than that of the under I $\mu$ particles. The difference between the I to $3 \mu$ and 2 to $5 \mu$ particles was, however, not pronounced.

Comparison of and Correlation between Right and Left Lungs with Respect to the Different Variables

Wet Weight of Lungs It was shown that the injection of silica dust into the lungs can greatly increase the weight of the lung which received the most silica.

Weight of Silica It was shown, as in the previous experiment (Goldstein et al., 1962), that the silica injected is seldom shared equally by the two lungs.

Weight of Collagen The quantities of collagen were usually larger in the right than in the left lungs for the under I $\mu$ and I to $3 \mu$ particles, but this bias was not present in the other group.

Correlation between the Variables, Wet Weight of Lungs, Weight of Silica, and Weight of Collagen No significant correlations (at the $5 \%$ level) were found in the under $\mathrm{I} \mu$ group, and the correlations which are significant at the $5 \%$ level for the other two groups are shown in Table V. 
TABLE V

\begin{tabular}{|c|c|c|c|}
\hline \multicolumn{4}{|c|}{ Correlations Significant at $5 \%$ Level } \\
\hline Variables & $\begin{array}{l}\text { Size } \\
\text { Fraction } \\
(\mu)\end{array}$ & $n$ & $\begin{array}{l}\text { Correlation } \\
\text { Coefficient }\end{array}$ \\
\hline Wet weight of lungs/Silica & $I-3$ & 24 & 0.44 \\
\hline Silica/Collagen & $1-3$ & 24 & 0.44 \\
\hline $\begin{array}{l}\text { Silica/Wet weight per roog. } \\
\text { body weight } \\
\text { Collagen/Wet weight }\end{array}$ & $I-3$ & 24 & 0.50 \\
\hline I00 g. body weight & $\mathbf{I}-3$ & 24 & 0.41 \\
\hline Wet weight of lungs/Silica & $2-5$ & 16 & 0.46 \\
\hline
\end{tabular}

\section{Discussion}

It was found that the two larger sized fractions of silica produced more fibrosis (histologically) than the under I $\mu$ particles and also produced a more marked increase of the wet weight of the lungs and the collagen content.

As the surface areas of the samples injected were the same for all the size-fractions, it appears that the reaction which occurs in the lungs is possibly related to the quantity (by weight) of the silica injected or the size of the particles and not to the total surface area.

A further experiment should now be undertaken to determine whether injections of equal weights of different sized particles produce similar degrees of fibrosis.

That the quantity of dust injected plays an important part in the production of fibrosis is further borne out by an experiment in which the under I $\mu$ particles were injected into animals in a higher concentration of $50 \mathrm{mg}$. per animal and the degree of fibrosis obtained was much more marked than when the surface area of $600 \mathrm{sq} . \mathrm{cm}$. per animal was used with only $13.99 \mathrm{mg}$. silica in each dose.
It is also interesting to note that, although $41 \%$ of under I $\mu$ particles injected was recovered as against $15 \%$ of the 2 to $5 \mu$ particles, the latter produced much more fibrosis. However, $4 \mathrm{I} \%$ of the under I $\mu$ particles would be equivalent to an average retention of $5.7 \mathrm{mg}$., while the $15 \%$ of the 2 to $5 \mu$ particles represents $13.9 \mathrm{mg}$. This could indicate that the more silica is retained, the greater the degree of fibrosis.

The differences between the two larger size fractions were not as marked as between these two sizes and the under I $\mu$ particles. It may be that the under I $\mu$ particles behave in a different manner from particles above $I \mu$, in which case comparison of the fibrogenic properties of dusts that are smaller and larger than I $\mu$ may have to be re-assessed.

The silica recoveries in this experiment were lower than in the previous experiments (Goldstein et al., 1962). This could be due to a combination of increased loss by regurgitation over the longer duration of the experiment and dissolution within the body.

We would like to thank Dr. H. S. Sichel, Director of the Operational Research Bureau, Johannesburg and his staff for the statistical analysis, and Mr. P. H. Kitto for the dust samples.

\section{REFERENCES}

Belt, T. H., and King, E. J. (1945). In Spec. Rep. Ser. Med. Res. Coun. (Lond.), No. 250, p. 29.

Goldstein, B. (1960). In Proceedings of the Pneumoconiosis Conference, Fohannesburg, 1959, p. 94. A. J. Orenstein, Ed. Churchill, London.

-, Webster, I., and Sichel, H. S. (1962). Brit. F. exp. Path., 43, 38.

King, E. J., Stacy, B. D., Holt, P. F., Yates, D. M., and Pick les, D. (1955). Analyst, 80, 44I.

Neuman, R. E., and Logan, M. A. (1950). f. biol. Chem., I84, 299. 